\title{
Characterization of isolated UV-C-irradiated mutants of microalga Chlorella vulgaris for future biofuel application
}

\author{
Jessa DG. Carino ${ }^{1} \cdot$ Pierangeli G. Vital $^{1}$ (D) \\ Received: 27 May 2021 / Accepted: 23 December 2021 / Published online: 4 January 2022 \\ (c) The Author(s), under exclusive licence to Springer Nature B.V. 2021
}

\begin{abstract}
Microalgae-based biofuel is considered as one of the most promising sources of alternative energy because it is sustainable and does not pose threats to the environment and food security. However, attempts in improving microalgal strains to attain the ideal characteristics for biofuel application are yet to unravel. In this study, random UV-C mutagenesis was employed to generate starch-deficient mutants of indigenous Chlorella vulgaris to enhance its productivity. Out of 872 colonies, two isolated mutants (cvm5 and cvm6) were isolated and showed significant increase in cell concentrations by $>1.47$-fold and $>1.04$ fold, respectively. However, mutant cells exhibited smaller in size which might contributed to the significant decrease in their biomass. Moreover, gathered data revealed that the total lipid content of cvm5 was enhanced significantly $(75 \%,>1.3$-fold increase). Additionally, triacylglycerol (TAG) content of the said mutant constitutes $48 \%$ of the dry cell weight (DCW) while cvm6 consist of $41 \%$ of the DCW. These promising and novel findings suggest that the two generated and isolated mutants are good candidates for future commercial biofuel production, especially in the Philippines. In addition, these findings may contribute on the prior knowledge of the usage of UV-C for microalgal strain development.
\end{abstract}

Keywords Biofuel $\cdot$ Chlorella vulgaris $\cdot$ Starchless mutants $\cdot$ Triacylglycerol $\cdot$ UV mutagenesis

\section{Introduction}

Rapid increase in population and long-term effects of anthropogenic activities relying on fossil fuels has led to rapid decrease of available resources and urgent global environmental concerns such as climate change (Amin, 2009; Khan et al., 2017). Even though the use of renewable energy such as wind, solar and hydroelectricity is growing widely and rapidly, $84 \%$ of world's primary energy consumption is from fossil fuels followed by hydroelectric, renewables and nuclear energy (Rapier, 2020). It has been reported by BP in its Statistical Review of World Energy 2020 that due to the COVID-19 pandemic, oil consumption

Pierangeli G. Vital

pgvital@up.edu.ph

1 Natural Sciences Research Institute, University of the Philippines Diliman, 1101 Quezon City, Philippines 
dropped by 9.1 million b/d in 2020 and stated that carbon emissions also dropped by $6.3 \%$. However, this rate of decline in carbon emissions should be maintained for the next 30 years to be able to meet the aims and comply with the Paris Agreement. Widespread air pollution and climate change due to excessive use of fossil fuels have led governments, public and private sectors to reduce carbon emissions (Global Commission on the Geopolitics of Energy Transformation, 2019). As of 2020, the Philippines consumed 391 thousand b/d (Statista, 2021). The promotion of renewable energies in many countries will help achieve their goals of decreasing the amount of carbon dioxide and saving the environment for the future generations (Simsek et al., 2019). Experts say that electricity price in the Philippines could decrease by $30 \%$ with the help of renewable energy (Saulon, 2019) and this is very significant as the economy continues to struggle especially during this time of pandemic.

As we continue to search for the best alternative source of energy, various types of sources have been studied to be an alternative feedstock for biofuel production. First generation biofuels are the most recognizable type of biofuel which includes vegetable oils, bio-alcohols, biodiesel, biogas and solid biofuels (Datta et al., 2019). These are crop plantbased which contain sugars, oils and cellulose and known to be utilized by humans for hundreds of years. On the other hand, second generation biofuels are also plant-based but generally are not used for human consumption. Second generation biofuels are known as "advanced biofuels" because production of its sources (wood, agricultural residues, organic wastes, food wastes and specific biomass crops) is very difficult (Berla et al., 2013). First and second generation biofuels are advantageous in terms of the wide variety of feedstock for manufacturing. However, such feedstocks impose public concerns since they compete with land use and generate more greenhouse gasses during their production processes (Ahmad et al., 2011). Third generation biofuels are from algal biomass and showed one of the most promising sources of sustainable and renewable energy (Naik et al., 2010). Studies show that they have relatively higher productivities, sustainable, and do not compete with land and food productions. Numerous researches that demonstrated the application of various microalgae species for mass cultivation and biofuel applications have been published (Chisti, 2007; Gour et al, 2014; Qi et al., 2018; Qiang et al., 2008; Rahman et al., 2020; Ramaraj et al., 2014; Xing et al., 2021). Microalgae are thallophytes, microscopic organisms which use chlorophyll $a$ as their primary photosynthetic pigment and are considered as one of the oldest living organisms (Ramaraj et al., 2014; Brennan \& Owende, 2010). Algae can either be autotrophic or heterotrophic. For optimal growth of autotrophic algae, carbon dioxide, salts and light energy source are necessary while heterotrophic algae require organic compounds for their source of energy (Demirbas, 2008; Brennan \& Owende, 2010). These organisms are known to have faster growth rate in bodies of water or ponds. Microalgae can be cultivated in open ponds, closed-loop systems and photobioreactors. Since they have shorter harvesting cycle and contain more lipids than macroalgae, they are a good source for biodiesel, butanol, gasoline, methane, ethanol, vegetable oil and jet fuel (Datta et al., 2019).

Microalgae as feedstock for third-generation biofuel production have been also receiving attention because of their ability to produce high amount of triacylglycerol (TAG), shorter generation time but rapid growth potential, and tolerance to environmental conditions, higher acceptance of carbon dioxide, wide variety of sources and do not compete with food and land use (Sheehan et al., 1978; Chisti, 2007; Qiang et al., 2008; Datta et al., 2019). Members of the genus Chlorella have always been used for mass cultivation because of their commercial use in the food and cosmetics industry. Chlorella have always been utilized for mass cultivation because of their significant features for biodiesel production 
and biomass recovery due to their high growth rate, photosynthetic efficiency and significant oil content (Borowitzka, 2013; Liang et al., 2009; Van Vandamme et al., 2012). One species that is suitable for cultivation and exploration is $C$. vulgaris. This species contains compounds such as proteins astaxanthin, $\beta$-carotene and nutritional polyunsaturated fatty acids (PUFA) (Chacon-Lee \& Gonzalez-Marino, 2010; Singh \& Cu, 2010). C. vulgaris can also tolerate different conditions and have the capability to resist against invaders (Liang et al., 2009; Pauline et al., 2006). Under stress conditions, $C$. vulgaris can accumulate up to $58 \%$ lipid content in the form of TAGs and is suitable for biodiesel production because of its fatty acid profile (Sarkar \& Shimizu, 2015; Yeh \& Chang, 2011).

However, despite these advantageous characteristics of the microalgae-derived biofuels, large-scale production is still difficult to achieve because of the higher need for agricultural development compared to traditional crops and the energy input for harvesting the algae comprise of $20-30 \%$ of the whole manufacturing process. Although there's a wide range for the algae cultivation, cultivation requires large quantity of water, nitrogen and phosphorus (Cuellar-Bermudez et al., 2015; Datta et al., 2019). Aside from these, it is expensive and wild type microalgae have either high growth rate but low lipid content or high lipid content but slow growth rate. In order to bridge the gap with the high-cost production, majority of the studies done are focused on finding and characterizing an ideal microalgal species and improving their cultivation techniques and conditions (Liu et al., 2015; Sheehan et al., 1978; Vigeolas et al., 2012). Promising oleaginous microalgae for large-scale lipid production must possess certain main characteristics: (1) fast growth rate; (2) robustness; (3) high lipid content; (4) ability to survive under different environmental conditions; (5) ability to grow in low-cost media; (6) good cell flocculation/settlement properties; (7) ease of downstream processing and lipid extraction; and (8) ease of genetic manipulations. Majority of the wild type microalgal species cannot meet these characteristics that is why strain improvement strategies are being done (Saxena, 2015). Some of the highly explored techniques for strain improvement are random mutagenesis, adaptive laboratory evolution (ALE), and genetic engineering (Doan \& Obbard, 2012). Random mutagenesis is one of highly explored strategies to attain high biomass and high lipid content in microalgal cells. Mutagenesis is a straightforward, inexpensive, requires little knowledge of the organism's genetic information, biochemical pathways, genetic regulation, needs few technical manipulations and the strains generated do not undergo strict legal concerns (Yen et al., 2013; Bellou et al., 2014; Nawrath \& Wu, 2018; Ottenheim et al., 2018). This technique is carried out by either exposing the organism to physical or chemical mutagens which cause alterations to the organism's DNA. Physical method includes the exposure of organism to radiation such as X-rays, gamma and ultraviolet (UV) rays (Zayadan et al., 2014) or atmospheric and room temperature plasma (ARTP). UV radiation at 250-290 nm can either induce deletion of A-T base pairs in the DNA or promote thymine dymers (Muthuraj et al., 2019). On the other hand, chemical method such as ethyl methane sulfonate (EMS) and nitrosomethyl guadinine (Bird \& Neuffer, 1987). This involves the use of chemicals which cause errors in base paring, deamination of purines and transitions, transversions, and frameshift mutations (Saxena, 2015). Compared to chemical mutagenesis, physical method of random mutagenesis such as UV mutagenesis rapid, effective and safe to environment. UV mutagenesis is a good method for microalgae breeding because it is flexible, can be easily manipulated and does not need genetic information of the target organism. de Jaeger et al. (2014) demonstrated an accumulation of $45 \% \mathrm{w} / \mathrm{w}$ triacylglycerol (TAG), a precursor in biofuel production, from starchless mutants of microalga Scenedesmus obliquus. Generally, starch and TAG have the same carbon precursor, the C3 pool, such as 3-phosphoglycerate (3PG) and glyceraldehyde 3-phosphate (GAP). Starch serves as the primary energy 
source while TAG is the secondary energy and electron sink (Hu et al., 2008). It was hypothesized that when the pathway of starch formation is blocked hence, TAG accumulation is enhanced. This was confirmed by the studies of (Li et al, 2010; Wang et al., 2009; de Jaegar et al., 2014; Breuer et al., 2013; Tran et al., 2019). While several studies have demonstrated the use of UV mutagenesis in improving algal lipid production, mechanism of TAG accumulation is yet to be understood and majority of studies just demonstrated that UV mutagenesis can just either improve the biomass or the lipid content for the microalgae (Fang et al., 2013; Liu et al., 2015; Srinivas \& Ochs, 2012).

In this study, our goals were to investigate and explore the potential enhancing effects of random UV mutagenesis on growth, lipid production, and TAG production using indigenous $C$. vulgaris. It is our aim to screen and isolate potential starchless mutants, generated from the random UV mutagenesis, with good quality growth performance and increased lipid and TAG content. This study also demonstrated simple experimental design and lowcost materials. Lastly, because Philippines is a developing country and in need of alternative renewable resources, our study is the first in the country that will be beneficial for the exploration for an additional alternative source of energy using indigenous microalgae.

\section{Methodology}

\subsection{Cultivation of Chlorella vulgaris}

Majority of the chemicals used in the experiments were analytical grade. $C$. vulgaris, strain ACC-UPLB-MNH CL1, was obtained from the Phycology Laboratory at the University of the Philippines Los Baños, Laguna, Philippines. The microalgae were placed in sterile Erlenmeyer flasks and maintained in BG-11 medium (Table 1). Summary for the general methodology of the study is illustrated in Fig. 1. The flasks containing microalgae were placed in an indoor algae cabinet and maintained at a temperature of $25( \pm 2)^{\circ} \mathrm{C}$ under a 12:12-h alternate light/dark photoperiod using two white fluorescent lights $(40 \mu \mathrm{mol} /$ $\mathrm{m}^{2} / \mathrm{s}$ intensity). The cultures were continuously aerated for the entire culture period (Tayaban et al., 2017) and were shaken five times daily or as needed to avoid the clumping of microalgal cells. The cultures were maintained and subcultured until mother cultures were established.

\subsection{Screening and isolation of mutants}

Algal samples with cell density of $2 \times 10^{5}$ cells $/ \mathrm{mL}$ were prepared by standardizing the cell density of the mother algal culture at the exponential phase $\left(2.5 \times 10^{6}\right.$ cells $\left./ \mathrm{mL}\right)$ using cell counting method. Ten milliliters of the standardized microalgal samples were collected. To determine the proper time of UV exposure, $0.1 \mathrm{~mL}$ aliquots were spread plated onto BG-11 agar medium using sterile L-shape glass rod and air dried for $30 \mathrm{~min}$. Then, algal cells were exposed under UV light inside a Class II Biosafety Cabinet (ESCO, Singapore). The distance of the plates below the UV lamp was set at $40 \mathrm{~cm}$. Exposure time was measured from 0 to $10 \mathrm{~min}$ with an interval of $30 \mathrm{~s}$. The intensity of UV irradiation for all setups was sustained by providing uniform distance and wavelength at each different exposure time. After each timepoints, the UV irradiated plates were immediately covered with foil and kept in the dark overnight to prevent light-induced DNA repair via photoreactivation. Afterwards, plates were placed under light incubation for 2-3 weeks or until there 
Table 1 BG-11 medium components used in cultivation of Chlorella vulgaris

\begin{tabular}{llll}
\hline Macronutrients & $\begin{array}{l}\text { Stock solution concentration } \\
(\mathrm{g} / 200 \mathrm{~mL})\end{array}$ & $\begin{array}{l}\text { Final concentration } \\
(\mathrm{mM})\end{array}$ & $\begin{array}{l}\text { Amount } \\
(\mathrm{mL} / \mathrm{L})\end{array}$ \\
\hline Sodium nitrate & 30 & 17.6 & 10 \\
Dipotassium hydrogen phosphate & 0.8 & 0.23 & 10 \\
Magnesium sulfate pentahydrate & 1.5 & 0.3 & 10 \\
Calcium chloride dihydrate & 0.72 & 0.24 & 10 \\
Sodium carbonate & 0.4 & 0.19 & 10 \\
Disodium magnesium EDTA & 0.02 & 0.0027 & 10 \\
Citric acid & 0.12 & 0.031 & 10 \\
Ferric ammonium citrate & 0.12 & 0.021 & 10 \\
\hline Trace metals & Amount $(\mathrm{g} / 1 \mathrm{~L})$ & Final concentration $(\mathrm{mM})$ \\
\hline Boric acid & 2.86 & 46 & \\
Manganese(II) chloride tetrahydrate & 1.81 & 9 & \\
Zinc sulfate heptahydrate & 0.22 & 0.77 & \\
Sodium molybdate dihydrate & 0.39 & 1.6 & \\
Copper(II) sulfate pentahydrate & 0.079 & 0.3 & \\
Cobaltous nitrate hexahydrate & 0.0494 & & \\
\hline
\end{tabular}

are visible colonies (Darunsart, 2014). Fatality rate (FR) was determined through colony counting method using hemocytometer (Neubauer chamber, Marienfeld, Germany) and calculated using the formula:

$$
\mathrm{FR}(\%)=\frac{\# \text { of viable colonies before mutation }-\# \text { of viable colonies after mutation }}{\# \text { of viable colonies before mutation }} \times 100
$$

Exposure time with fatality rate of 75-90\% was chosen (Liu et al., 2015). After determining the proper UV exposure time, mutant colonies were initially screened based on their size and color. Larger colonies and greener colonies were chosen and streaked onto BG-11 agar medium. Then, each of these colonies was further screened through iodine staining method to determine potential starch-deficient mutants (which were designated as "cvm"). Colonies that exhibited lighter color compared to the wild type were selected for mass cultivation. Selected mutants were upscaled in sterile Erlenmeyer flasks with BG-11 medium under two white fluorescent lights with $40 \mu \mathrm{mol} / \mathrm{m}^{2} / \mathrm{s}$ intensity and 12:12-h light and dark incubation. All cultures were aerated and maintained at $25( \pm 2)^{\circ} \mathrm{C}$ until mother cultures for each starchless mutants have been established.

\subsubsection{Growth analysis}

Algal samples of wild type and mutants were standardized to attain $1 \times 10^{6}$ cells $/ \mathrm{mL}$ and maintained under the abovementioned conditions for 7 days for analysis. For growth curve analysis, $1 \mathrm{~mL}$ of the algal samples was collected and placed in a $1.5 \mathrm{~mL}$ microcentrifuge tube. A total of $10 \mu \mathrm{L}$ were pipetted out and transferred into a hemocytometer (Neubauer chamber, Marienfeld, Germany) for cell counting. Cell density of each sample in triplicates was calculated using the formula: 


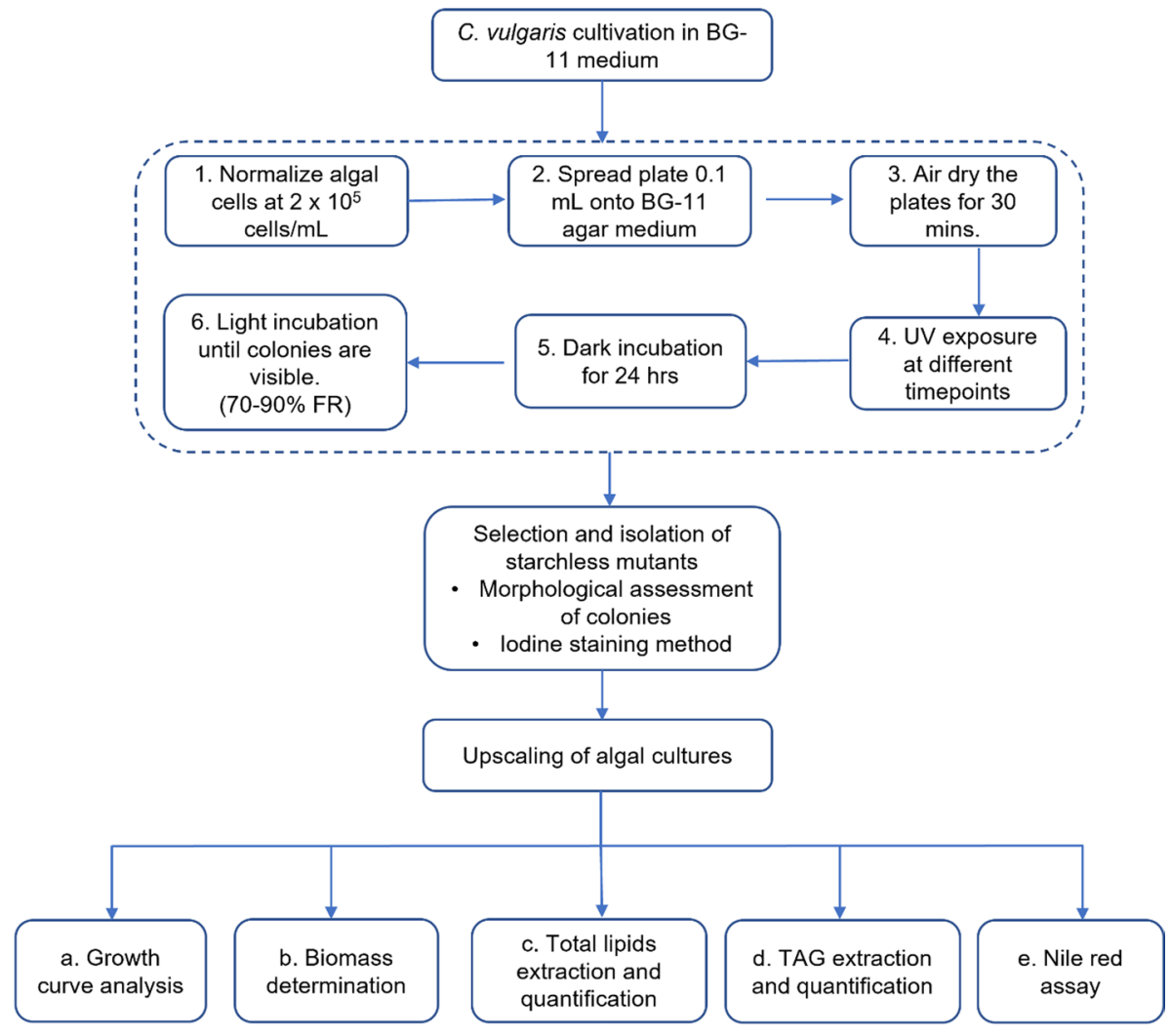

Fig. 1 Flow diagram of the methodology for the UV irradiation, mutant selection and analysis

$$
\text { Cell density }(\text { cells } / \mathrm{mL})=\frac{\text { Average no. of cells per square } \times \mathrm{DF}}{\text { Volume of the square }\left(0.1 \mathrm{~mm}^{3}\right)}
$$

Cell density of each algal samples (Log10) was plotted against time (days). Then, maximum specific growth rate per day $\left(\mu_{\max }, \mathrm{d}^{-1}\right)$ was determined using the equation below:

$$
\mu_{\max }=\frac{\ln \left(\frac{N 2}{N 1}\right)}{t 2-t 1}
$$

where $\mu$ represents the specific growth rate per day; $t 2$ and $t 1$ are the final and initial time and $N 2$ and 11 are the final and initial cell densities. Doubling time $\left(T_{\mathrm{d}}\right)$ and doublings per day ( $K$; number of divisions per day) were also calculated using the following formulas:

$$
\begin{gathered}
T_{\mathrm{d}}=\frac{\ln 2}{\mu_{\text {max }}} \\
K=\frac{\mu_{\text {max }}}{\ln 2}
\end{gathered}
$$


For the determination of the dry biomass, a total of $10 \mathrm{~mL}$ per algal sample were harvested from day 0 and day 7 . These were filtered using a pre-weighed filter paper (Whatman No. 2) and dried overnight inside an oven incubator at $37^{\circ} \mathrm{C}$. Formula used are as follows:

$$
\begin{gathered}
\text { Biomass }(\mathrm{g} / \mathrm{L})=\frac{\text { Final weight }(\mathrm{g})-\text { Initial weight }(\mathrm{g})}{\operatorname{Volume}(\mathrm{L})} \\
\text { Biomass productivity }(\mathrm{mg} / \mathrm{L} / \text { day })=\frac{\text { Dry cell weight }(\mathrm{mg} / \mathrm{L})}{t(\text { day })}
\end{gathered}
$$

\subsubsection{Total lipid extraction and quantification by gravimetric method}

After 7 days of cultivation, wild type and mutants' algal cells were harvested and centrifuged at $3000 \mathrm{rpm}$ for $10 \mathrm{~min}$. The cell pellets were placed in $-20{ }^{\circ} \mathrm{C}$ freezer for $48 \mathrm{~h}$ and lyophilized. All chemicals used for the total lipid extraction were analytical grade. Extraction was accomplished by following the protocol of Breuer et al. (2013) with few modifications. A total of $15 \mathrm{mg}$ of lyophilized algal cells were placed in a bead beating tube containing 4:5 (v/v) chloroform: methanol with $50 \mathrm{mg} / \mathrm{L}$ heptadecanoic acid to avoid lipid losses. Tubes were vortexed $8 \times$ at $2400 \mathrm{rpm}$ for $1 \mathrm{~min}$, with a 2 -min interval between each beating. The resulting solution and beads were transferred into a clean glass test tube covered with a heat resistant screw cap. To recover all lipids, bead beating tubes were washed twice with $1 \mathrm{~mL}$ chloroform:methanol with heptadecanoic solution. Samples were vortexed for $10 \mathrm{~s}$ and sonicated for $10 \mathrm{~min}$ at $45^{\circ} \mathrm{C}$. Subsequently, $2 \mathrm{~mL}$ ultrapure water and $1 \mathrm{~mL} 0.01 \%$ BHT were added. The solution was then centrifuged at $3000 \mathrm{rpm}$ for $5 \mathrm{~min}$. Chloroform phase (bottom) was collected using a glass pipette and transferred into a preweighed vial. Extraction of lipids was repeated $2 \times$ with $1 \mathrm{~mL}$ chloroform. Pre-weighed vials containing the extracted lipids were oven-dried overnight and dried lipids were measured gravimetrically:

$$
\text { Lipid content }(\%)=\frac{\text { Weight of lipid }(\mathrm{g}) \times 100}{\text { dry cell weight }(\mathrm{g})}
$$

\subsubsection{TAG extraction by solid phase extraction and gravimetric quantification}

A total of $10 \mathrm{mg}$ of dried lipids was dissolved in $250 \mu \mathrm{L}$ HPLC grade hexane. TAGs were purified using Solid Phase Extraction kit (Phenomenex, USA). Each cartridge was prewashed with $6 \mathrm{~mL}$ hexane before loading the sample. TAGs were eluted with $10 \mathrm{~mL}$ of 87:13 (\%v/v) hexane:diethyl ether. Collected TAGs were placed in pre-weighed vials and let dried overnight. TAG content was calculated using the formula:

$$
\text { TAG content }(\%)=\frac{\text { Weight of TAGs }(\mathrm{g}) \times 100}{\text { dry cell weight }(\mathrm{g})}
$$

\subsubsection{In situ visualization of intracellular lipid bodies by Nile red assay}

Lipophilic dyes such as the Nile red (9-diethylamino-2-hydroxy-5H-benz[alpha]phenoxazin-5-one) are widely used to visualize intracellular lipid bodies by binding to neutral 
lipids. In this experiment, Nile red assay was performed following the protocol of Chen et al. (2011). After 7 days cultivation, $1 \mathrm{~mL}$ of algal cells was collected into $1.5 \mathrm{~mL}$ centrifuge tubes and centrifuged at $3000 \mathrm{rpm}$ for $10 \mathrm{~min}$. Then, $50 \mu \mathrm{L}$ of DMSO was added and tubes containing the solution were placed inside a microwave set at high for $1 \mathrm{~min}$ to dissolve the polar lipids and destroy the membranes. Simultaneously, $935 \mu \mathrm{L}$ of pure water and $10 \mu \mathrm{L}$ Nile red dye were added and heated in the microwave for $1 \mathrm{~min}$. For the image analysis, $10 \mu \mathrm{L}$ of the algal cells-Nile red solution was placed in a clean glass slide and covered with cover slip. The slides were examined at $100 \times$ magnification with a fluorescence microscope (Olympus BX43F with 365/10 excitation, 420LP emission, and 400LP dichroic mirror, and $120 \mathrm{~W}$ mercury vapor arc lamp; Shinjuku, Tokyo, Japan).

\subsubsection{Data analysis}

Data were expressed as mean \pm standard deviation. Statistical analysis was performed using GraphPad Prism version 9.1.0. (GraphPad Software, San Diego, CA, USA) software. The means of each mutant in triplicates were compared to the wild type using one-way analysis of variance (ANOVA). Values were significantly different when $p<0.05$.

\section{Results and discussion}

\subsection{UV-irradiation and mutant selection}

This study aims to explore the influence of random UV mutagenesis to produce starchless mutants of indigenous microalgae $C$. vulgaris with high growth rate, lipid and TAG content that would be beneficial for future biofuel research. In this study, fatality rate of $75-90 \%$ has been indicated to have a significant mutagenic impact in algal cells (Liu et al., 2015). As observed in Fig. 2, the fatality rate increased from $84 \%$ upon exposure to UV light after $0.5 \mathrm{~min}$. Subsequently, it abruptly increased to $99 \%$ after 1 min of exposure and no colonies were observed from 1.5 to $10 \mathrm{~min}$. This indicates that the longer exposure time to UV, the more lethal it is to the microalgal cells. Microalgal cells that remained viable after the exposure to UV usually have an altered genetic code for reprogrammed metabolic and biosynthetic activity (Parekh et al., 2000). UV mutagenesis technique can cause mutations such as transversion, deletion, frameshift

Fig. 2 Exposure of Chlorella vulgaris cells to UV light at different timepoints. Fatality rate of $84 \%$ at $0.5 \mathrm{~min}$ was established through colony counting method. Error bars represent standard deviation of triplicate samples

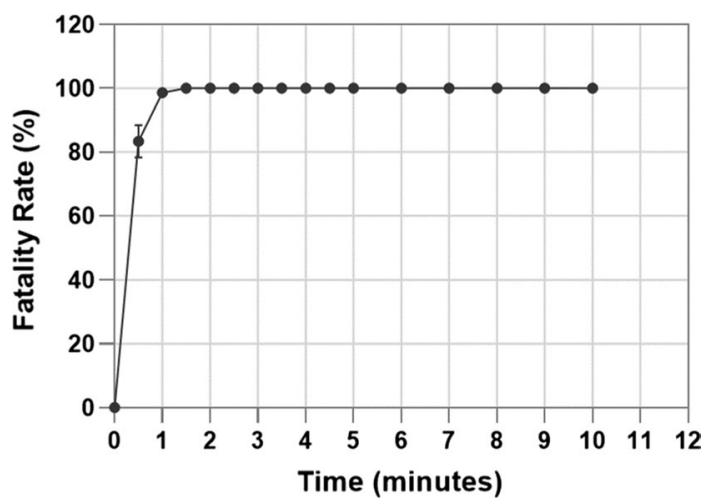


and GC $\rightarrow$ AT transitions (Parekh et al., 2000) that affect the growth, photosynthesis, biochemical composition, nutrient uptake, reproduction and other physiological processes in the organism (Hader, 2006; Helbling et al., 2001; Hughes, 2006; Shelly et al., 2005; Wong et al., 2007). UV-C with a wavelength of $253.7 \mathrm{~nm}$ was used in this study to induce mutagenesis. It is believed that $\mathrm{UV}-\mathrm{C}$ has more energetic radiation and has significant effects on microalgae (Sharma et al., 2014). The said wavelength gave higher possibility of DNA damage in the organism and therefore higher chance of induced mutation. It has also been noted that the irradiated $C$. vulgaris cells were kept in the dark for $24 \mathrm{~h}$ before incubating under the light. This is because DNA replication errors are more frequent, hence, causing various mutations in the organism (Vaulina et al., 1978). Exposure duration of 0.5 min with fatality rate of $84 \%$ was chosen which is also in consideration of the cell activity for the succeeding mass cultivation and analyses.

Approximately 872 colonies were obtained after the UV irradiation and 104 of these were initially selected visually based on colony size and color for the succeeding screening test. Since the goal of the study is to produce a highly productive strain, only larger and green color colonies were taken into consideration. These were then replicated onto BG-11 agar and were screened for the absence of starch using iodine staining method. Initially, 13 colonies that showed the lightest color compared to the wild type were selected and upscaled. However, 11 of these showed poor growth performance, discoloration and frequent clumping of cells during the cultivation period which might be due to the mutation that affected their growth. Aside from this, it is believed that exposure to UV-C radiation induces programmed cell death (PCD) (Danon \& Gallois, 1998) and this might be the cause of the inability of the mutant algal cells to proliferate when cultivated. In addition, there is also a reduction in the capacity of the microalgae to absorb macronutrients (Hessen et al., 1997) that are responsible for biochemical changes in the microalgae (Khozin-Goldberg \& Cohen, 2006). Nevertheless, there were two mutants, designated as cvm5 and cvm6, that showed promising growth performance. As shown in Fig. 3, wild type (WT) cells showed dark brown violet color while cvm5 appeared to be greenish brown and cvm6 as yellowish brown. For this experiment, the change of color from the usual dark to a lighter one is considered to have lesser starch, however, starch content was not measured in this study (Sirikhachornkit et al., 2016). Screening and isolation of potential starchless mutants after the UV irradiation technique was done since it is believed that when the pathway of starch formation is blocked, TAG molecules is enhanced ( $\mathrm{Li}$ et al., 2010; Wang et al., 2009). de Jaeger et al. (2014) successfully isolated starchless mutants of freshwater microalga S. obliquus through random UV-mutagenesis which exhibited enhanced lipid accumulation. Most studies that involve the increase accumulation in starchless mutants had emphasized the increased in carbon allocation toward lipid metabolism. In addition, the increase peroxidation in algal cells with impaired starch metabolism may also trigger lipid buildup (Tran et al.,

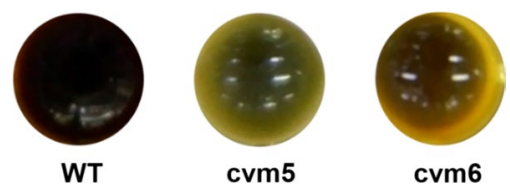

Fig. 3 Mutant selection through iodine staining method. Isolates that exhibited the lightest color compared to the wild type were selected. Isolates cvm5 and cvm6 showed greenish brown and yellowish brown, respectively. The light color indicates reduction in starch 


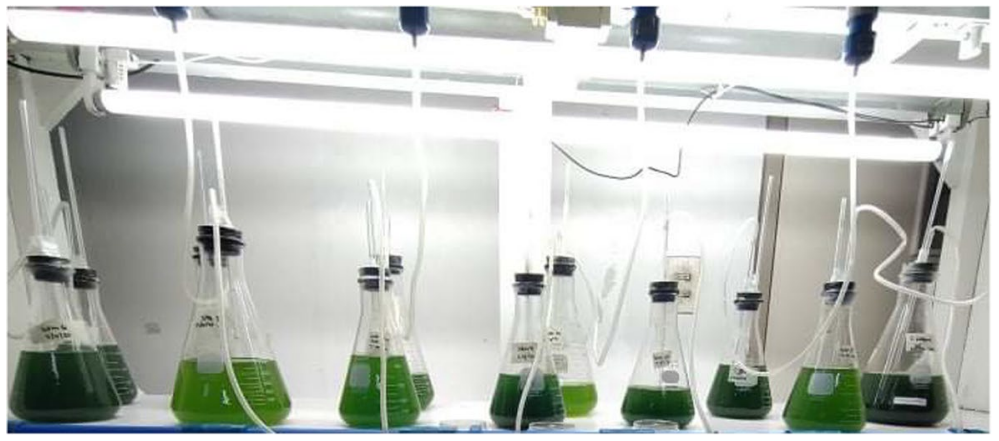

Fig. 4 Cultures were maintained under $25( \pm 2)^{\circ} \mathrm{C}$ with $12: 12$-h alternate light/dark photoperiod using two white fluorescent lights $\left(40 \mu \mathrm{mol} / \mathrm{m}^{2} / \mathrm{s}^{1}\right.$ intensity) and with continuous aeration

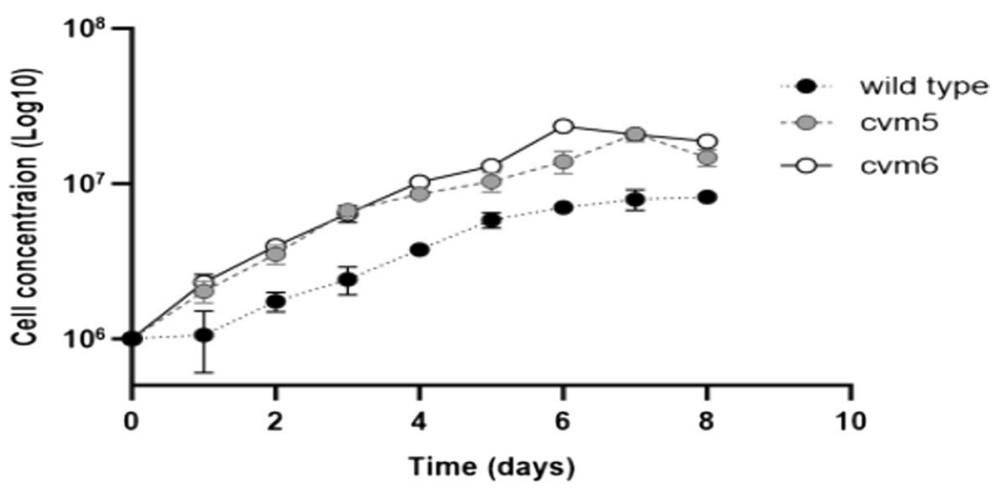

Fig. 5 Growth curve of $C$. vulgaris WT, cvm5 and cvm6 after 7 days of cultivation in BG-11 medium. Cultures were optimized at initial cell density of $1 \times 10^{6}$ cells $/ \mathrm{mL}$. Growth curve was plotted as cell concentration (Log 10) against time (days). Plotted values are the average cell density \pm standard deviation $(n=3)$

2019). Direct effect of UV mutagenesis in the starch and lipid pathway is still yet to dig deeper. Still, this is an important and crucial step for our succeeding measures.

\subsection{Growth analysis of wild type and mutants}

After the mutant selection and establishment of cultures was attained by maintaining each under uniform conditions (Fig. 4). For their growth performance analysis, cells were standardized to $1 \times 10^{6}$ cells $/ \mathrm{mL}$ and were then monitored for 7 days. It is also important to take note that all cultures received uniform amount of light, air and temperature. Growth curve was generated by plotting the cell density (Log10) against time (days). As shown in Fig. 5, algal cell count of cvm5 and cvm6 were significantly enhanced compared to the WT $(p<0.05)$. cvm5 recorded its highest cell count with $2.08 \pm 0.23 \times 10^{7}$ cells $/ \mathrm{mL}$ while of cvm6 with $2.33 \pm 0.13 \times 10^{7}$. This is a $>2.8$-fold and $>3.2$-fold increase compared to the WT with $7.28 \pm 0.81 \times 10^{6}$ as it highest recorded cell concentration. WT $C$. vulgaris entered the exponential phase at $\mathrm{d} 2$ and extended up to $\mathrm{d} 5$. It can be noted that WT setup gradually reached stationary phase at d6. On the other hand, cvm5 and cvm6 started their exponential phases at d1 and d2, respectively. 
Isolate cvm5 immediately increased in cell count on $\mathrm{d} 1$ and progresses until day 7 while cvm6 abruptly decreased in cell concentration at the end of the cultivation period. It can be observed that all setups have no lag phases, and this may be due to the sufficient nutrient supply in the initial days of the cultivation period. Maximum specific growth rate signifies the specific growth rate during exponential growth (Doran, 2013). On the other hand, doubling time is the expected amount of time $\left(\mathrm{d}^{-1}\right.$ or $\left.\mathrm{h}^{-1}\right)$ it takes for a given population to double in size. Presented in Table 2 are the growth parameters measured in this study. Only the cvm5 showed statistically significance in terms of maximum growth rate, doubling time and doubling per day compared to the wild type $(p<0.05)$. As supported, results showed that the growth rate of cvm5 $(\mu=0.601)$ has increased by $>1.47$-fold as compared to the WT $(\mu=0.409)$. Significant difference can also be observed between the two mutants. Though cvm6 showed no significance in comparison to the wild type, its growth rate $(\mu=0.427)$ was still enhanced by $>1.04$-fold. Though not measured in this study, increase of Chl- $a$ components can also be considered why cvm5 and cvm6 showed high cell density and fast growth rate. Usually, higher Chl- $a$ content leads to the enhancement of photosynthesis and speeding up of cell division process (Liu et al., 2015). Looking again at Table 2, biomass of the two mutants in this study has significantly lower biomass compared to the WT $(0.421 \pm 0.069)$. cvm5 decreased in biomass by $>1.2$-fold while cvm6 by $>1.3$-fold. In addition, biomass productivity of cvm5 $(25.3 \pm 0.045)$ and cvm6 (27.3 \pm 0.029$)$ showed comparably decline in contrast with the WT. The differences between the total biomass and biomass productivity of WT and mutants were both significant at $p<0.05$. It can be observed that the two mutants have relatively higher cell concentration and growth rate compared to the WT, however, their biomass are still compromised. One reason to be taken into consideration would be the difference in their cell sizes. It was noticed that cvm5 and cvm6 are smaller in size compared to the WT. This might be due to the random mutagenesis employed which caused physiological and morphological changes in the mutants. Reed Mariculture (n.d.) stated that there is a huge difference in cell biomass that is brought about by the small difference in cell size and an increase in $10 \%$ in diameter would mean $33 \%$ increase in the biomass. Additionally, the results of the study conducted by Abonyi et al. (2020) also suggest that decrease in algal size limits algal biomass production.

Table 2 Maximum specific growth rate, doubling time, doubling per day, biomass and biomass productivity of $C$. vulgaris wild type (WT), cvm5 and cvm6

\begin{tabular}{llllll}
\hline Cultures & $\begin{array}{l}\text { Specific growth } \\
\text { rate }\left(\mu_{\max }, \mathrm{d}^{-1}\right)\end{array}$ & Doubling time $\left(T_{\mathrm{d}}\right)$ & Doubling per day $(\mathrm{K})$ & Biomass $(\mathrm{g} / \mathrm{L})$ & $\begin{array}{l}\text { Biomass pro- } \\
\text { ductivity mg/L/ } \\
\text { day }\end{array}$ \\
\hline WT & $0.409 \pm 0.033$ & $1.703 \pm 0.133$ & $0.590 \pm 0.047$ & $0.421 \pm 0.069$ & $40.6 \pm 0.040$ \\
cvm5 & $0.601 \pm 0.083$ & $1.167 \pm 0.150$ & $0.867 \pm 0.120$ & $0.330 \pm 0.023$ & $25.3 \pm 0.045$ \\
cvm6 & $0.427 \pm 0.026$ & $1.629 \pm 0.096$ & $0.615 \pm 0.037$ & $0.318 \pm 0.024$ & $27.3 \pm 0.029$ \\
\hline
\end{tabular}

Values are the average \pm standard deviation $(n=3)$ 


\subsection{Lipid and TAG content analysis of WT, cvm5 and cvm6}

\subsubsection{Effects of UV in lipid and TAG content, carbon allocation}

Biofuel production from microalgae is divided into four stages: (a) cultivation, (b) harvesting, (c) lipid extraction and transesterification for biodiesel production and (d) fermentation, starch hydrolysis and distillations for bioethanol production (Milano et al., 2014). Lipids and fatty acids are extracted from the biomass and solvents such as hexane and ethanol are used and $98 \%$ of purified fatty acids can be potentially obtain in this procedure (Richmond, 2004). Lipids have two types: storage lipids (nonpolar lipids) and structural lipids (polar lipids). Storage lipids are mainly in the form of triacylglycerol (TAG) while structural lipids are seen in algal membranes. TAGs can be transesterified to produce biodiesel (Durrett et al., 2008). In this study, the total lipids and TAG content of the WT, cvm5 and cvm6 were determined. Several methods can be used in quantifying lipids. Fluorescent dyes such as the 9-diethylamino-2-hydroxy-5H-benz[alpha]phenoxazin-5-one Nile Red (NR) are commonly used in staining intracellular lipid globules and in indirect measurement of lipid content in microalgae. A result of red to yellow color can be observed under a fluorescent microscope or flow cytometry (Diaz et al., 2008; Rumin et al., 2015). Presented in Fig. 6 are some of the representative fluorescence microscopy images of intracellular lipid bodies after the 7-d cultivation period. Lipid bodies were apparently abundant especially in cvm5 wherein the cells are 50-70\% covered with lipid bodies. Cvm6 and WT were also covered with lipid bodies of around $30-40 \%$ of the cells. Moreover, most of the

Fig. 6 Left to right: Bright field microscopy. Lipid fluorescence (Nile Red), a WT, b cvm5 and c cvm6
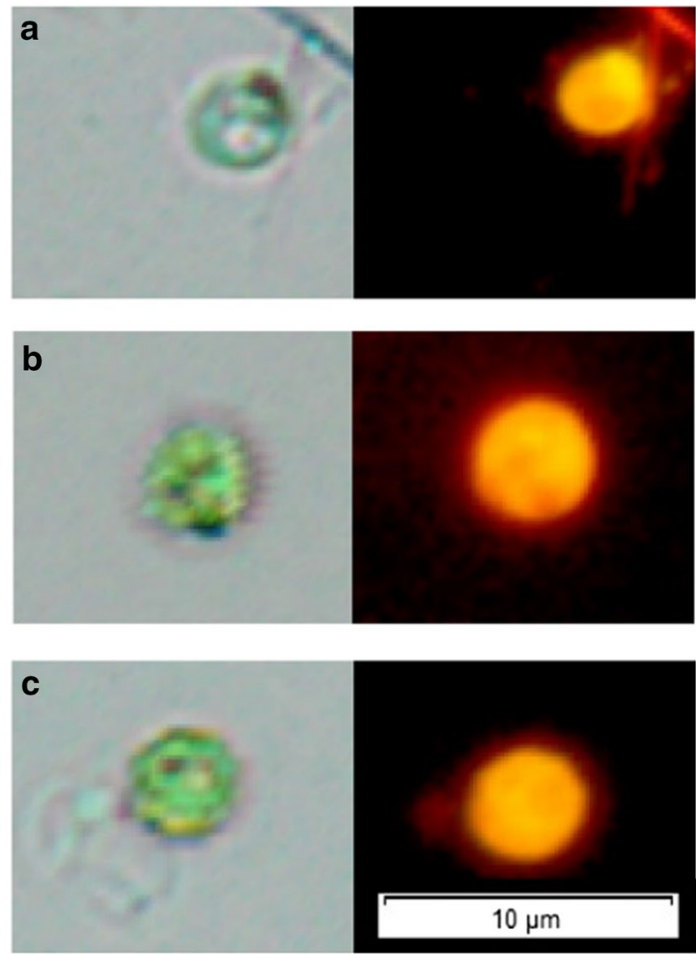
cells of the two mutants showed some morphological changes such as smaller in size and cell shape distortions. WT cells are larger and darker in color compared to cvm5 and cvm6. Generally, there is a balance between the pigment content of algae. However, if mutagenic agent has been introduced, this balance would exchange in either direction (Zaydan et al., 2014). Since this method was done for qualitative analysis only, lipid and TAG content were quantified gravimetrically. Data revealed that the increase in lipids between the WT and cvm5 were significant at $p<0.05$ (Fig. 7a). Total lipids of the WT C. vulgaris constitute $58 \%$ of the total dry weight. Lipid content of the cvm5 significantly increased by $17 \%$ (>1.3-fold increase) compared to the WT. Isolate cvm6 with 50\% total lipid content showed no significant difference with the WT and showed considerably lower lipid content compared to the cvm5. Microalgae accumulate and store neutral lipids in the form of triacylglycerols (TAGs) (Zhu et al., 2016). TAGs are preferred for biodiesel production due to their high content $(\% \mathrm{w} / \mathrm{w})$ of fatty acids (glycerol backbone with three fatty acids). In addition, the absence of other chemical constituents besides glycerol, compared to phospholipids or glycolipids, make them good precursor of biodiesel (Breuer et al., 2013). In this study, cvm5 TAG content was enhanced and constitute $48 \%$ the dry cell weight $(p<0.01)$ while cvm6 constitute $41 \%(p<0.05)$. These were $>1.4$-fold and $>1.2$-fold increase compared to the $34 \%$ TAG content of the wild type $C$. vulgaris (Fig. 7b). Genetic modification in microalgal cells can change certain cellular metabolic pathways. This can enhance or reduce specific metabolite production that may lead to increase lipid accumulation. One technique is by altering the starch biosynthesis pathway (Tran et al., 2019). de Jaeger et al. (2014) successfully isolated starchless mutants through random UV irradiation technique which exhibited enhanced lipid content accumulation. It was also hypothesized that when the pathway toward starch production is impeded, carbon and energy flux toward TAG
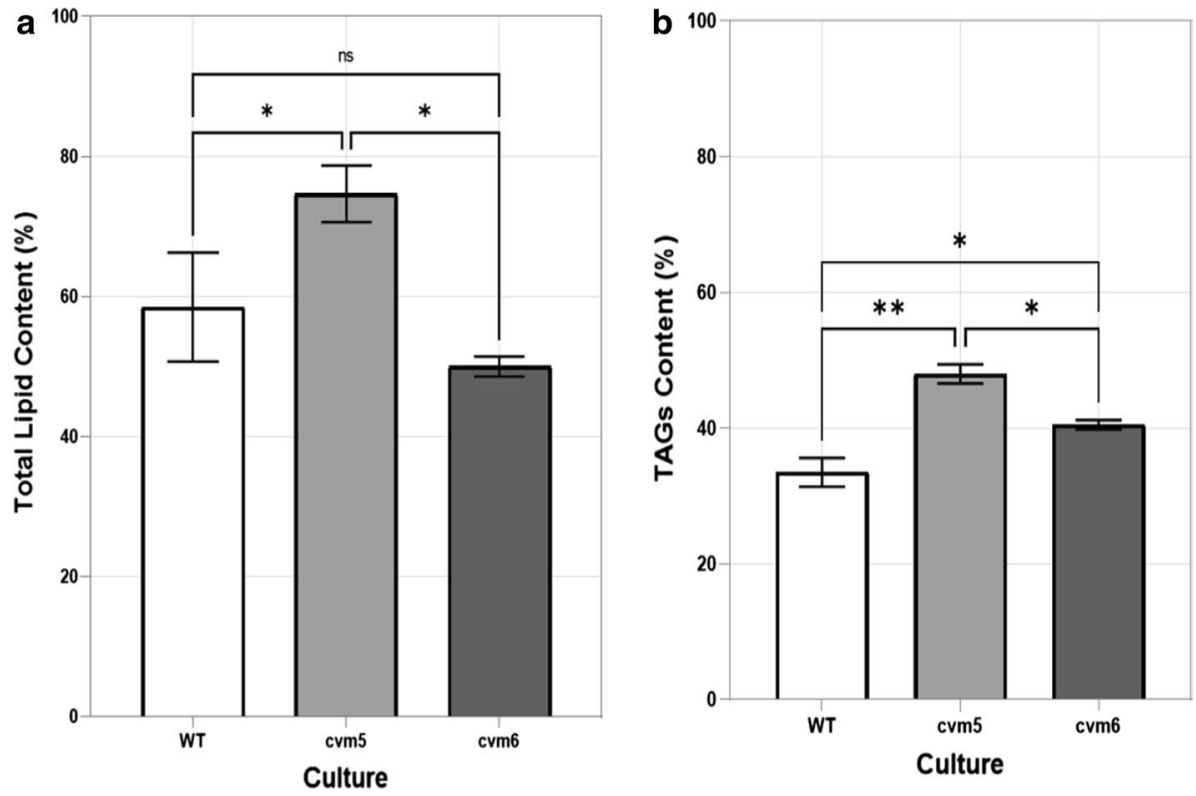

Fig. 7 a Total lipid content and b TAG content (\%) of WT, cvm5 and cvm6 after 7 days of cultivation. a Error bars are $\pm \mathrm{SD}(n=3) ; \mathbf{b} n=2$. *Signifies a significant difference calculated by one-way ANOVA $(p<0.05)$; **Significant $(p<0.01)$; $n s$ not significant 
production is improved. This was confirmed by the results of Li et al. (2010) studies where TAG content of the starchless mutants increased from 0.5 to $20.5 \%$ (\% of DW). Increase in lipid accumulation can also be attained when algal cells with impaired starch metabolism, which is due to random UV mutagenesis, the cells need to cope with elevated oxidative stress. Increase in ROS levels and as autophagy inducers may trigger lipid biosynthesis in mutants (Tran et al., 2019). These coincide with our results wherein both lipid and TAG yields were improved in the UV-generated mutants, most especially with the cvm5.

\section{Conclusion}

Based on the results obtained, random mutation through UV-C irradiation is a good technique for the alteration of cellular behavior toward the generation of starch-deficient mutants of $C$. vulgaris. Moreover, this leads to higher growth rate, increase in total lipid and TAG content of the microalgae. To our knowledge, this is the first in the country to deal with this type of study. These findings highlights the potential of the isolated mutants for future in-depth study and strain development to be used for biofuel application in the future.

Authors' contributions All authors contributed to the study conception and design. Material preparation, data collection and analysis were performed by Jessa DG. Carino and Pierangeli G, Vital. The first draft of the manuscript was written by Jessa DG. Carino and Pierangeli G. Vital edited and finalized the manuscript. All authors read and approved the final manuscript.

Funding This work was supported by the Natural Sciences Research Institute, University of the Philippines Diliman (Project Code: NSR-19-1-03).

\section{Declarations}

Conflict of interest The authors declare that they have no conflict of interest.

Consent for publication The authors consent the journal and publisher to publish the manuscript once accepted.

\section{References}

Abonyi, A., Kiss, K. T., Hidas, A., et al. (2020). Cell size decrease and altered size structure of phytoplankton constrain ecosystem functioning in the middle Danube River over multiple decades. Ecosystems, 23, 1254-1264. https://doi.org/10.1007/s10021-019-00467-6

Ahmad, A., Yasin, N. M., Derek, C., \& Lim, J. (2011). Microalgae as a sustainable energy source for biodiesel production: A review. Renew. Sustainable Energy Rev, 15, 584-593.

Amin, S. (2009). Review on biofuel oil and gas production processes from microalgae. Energy Conversion and Management, 50, 1834-1840.

Bellou, S., Baeshen, M. N., Elazzazy, A. M., Aggeli, D., Sayegh, F., \& Aggelis, G. (2014). Microalgal lipids biochemistry and biotechnological perspectives. Biotechnology Advances, 32, 1476-1493.

Berla, B. M., Saha, R., Immethun, C. M., Maranas, C. D., Moon, T. S., \& Pakrasi, H. B. (2013). Frontiers in Microbiology, 4, 246.

Bird, R. M., \& Neuffer, M. G. (1987). Induced mutations in maize. In: Janick, J. (Ed.), Plant breeding reviews (pp. 139-180). Van Nostrand Reinhold. https://doi.org/10.1002/9781118061022.ch5.

Borowitzka, M. A. (2013). High-value products from microalgae-Their development and commercialization. Journal of Applied Phycology 25:743-756. https://doi.org/10.1007/s10811-013-9983-9. 
Brennan, L., \& Owende, P. (2010). Biofuels from microalgae-A review of technologies for production, processing, and extractions of biofuels and co-products. Renewable and Sustainable Energy Reviews., 14, 557-577. https://doi.org/10.1016/j.rser.2009.10.009

Breuer, G., Evers, W. A., de Vree, J. H., Kleinegris, D. M., Martens, D. E., Wijffels, R. H., \& Lamers, P. P. (2013). Analysis of fatty acid content and composition in microalgae. Journal of Visualized Experiments: Jove, 80, 50628. https://doi.org/10.3791/50628

Chacon-Lee, T. L., \& Gonzalez-Marino, G. E. (2010). Microalgae for "Healthy" foods-possibilities and challenges. Comprehensive Reviews in Food Science and Food Safety, 9(6), 655-675.

Chisti, Y. (2007). Biodiesel from microalgae. Biotechnology Advances, 25, 294-306. https://doi.org/10. 1016/j.biotechadv.2007.02.001

Cuellar-Bermudez, S. P., Garcia-Perez, J. S., \& Rittmann, B. E. (2015). Clean. Prod., 98, 53. https://doi. org/10.1016/j.jclepro.2014.03.034

Danon, A., \& Gallois, P. (1998). UVC radiation induces apoptotic-like changes in Arabidopsis thaliana. FEBS Letters, 437, 131-136. https://doi.org/10.1016/S0014-5793(98)01208-3

Darunsart, P. (2014). Isolation and characterization of starch-deficient algal mutants of Chlorococcum humicola (pp. 34-67). Mahidol University.

Datta, A., Hossain, A., \& Roy, S. (2019). An overview on biofuels and their advantages and disadvantages. Asian Journal of Chemistry, 31(8), 1851-1858.

de Jaeger, L., Verbeek, R. E., Draaisma, R. B., et al. (2014). Superior triacylglycerol (TAG) accumulation in starchless mutants of Scenedesmus obliquus: (I) mutant generation and characterization. Biotechnology for Biofuels, 7, 69. https://doi.org/10.1186/1754-6834-7-69

Demirbas, A. (2008). Energy Conversion and Management, 49, 2106. https://doi.org/10.1016/j.encon man.2008.02.020

Diaz, G., Melis, M., Batetta, B., Angius, F., \& Falchi, A. M. (2008). Hydrophobic characterization of intracellular lipids in situ by Nile Red red/yellow emission ratio. Micro, 39(7), 819-24. https://doi. org/10.1016/j.micron.2008.01.001

Doan, T. T. Y., \& Obbard, J. P. (2012). Enhanced intracellular lipid in Nannochloropsis sp. via random mutagenesis and flow cytometric cell sorting. Algal Research, 1, 17-21.

Doran, P. 2013. Homogenous Reactions. In: Doran P. (Ed), Bioprocess engineering principles, $2 \mathrm{nd}$ ed. (pp. 599-703). Academic Press. https://doi.org/10.1016/B978-0-12-220851-5.00012-5.

Durrett, T., Benning, C., \& Ohlrogge, J. (2008). Plant triacylglycerols as feedstocks for the production of biofuels. The Plant Journal, 54, 593-607.

Fang, M., Jin, M., Zhang, C., Tan, Y., Jiang, P., Nan, G., Heping, Li., \& Xing, X. (2013). Rapid mutation of spirulina platensis by a new mutagenesis system of atmospheric and room temperature plasmas (ARTP) and generation of a mutant library with diverse phenotypes. PLoS One, 8(e77016), 1-12. https://doi.org/10.1371/journal.pone.0077046.

Global Commission on the Geopolitics of Energy Transformation. (2019). A New World. The Geopolitics of the Energy Transformation; International Renewable Energy Agency: Masdar, Arab.

Gour, R. S., Kant, A., \& Chauhan, R. S. (2014). Screening of microalgae for growth and lipid accumulation properties. J. Algal Biomass Utln, 5(1), 38-46.

Hader, D. P. (2006). Impact of UV radiation on the aquatic environment. In: Environmental UV radiation: Impact on ecosystem and human health and predictive models (pp. 179-191). Netherlands: Springer. https://doi.org/10.1007/1-4020-3697-3_14.

Helbling, E. W., Villafane, V. E., Buma, A. G. J., Andrade, M., \& Zaratti, F. (2001). DNA damage and photosynthetic inhibition induced by solar ultraviolet radiation in tropical phytoplankton (Lake Titicaca Bolivia). European Journal of Phycology, 36, 157-166. https://doi.org/10.1017/S096702620 1003122

Hessen, D. O., De Lange, H. J., \& Van Donk, E. (1997). UV-induced changes in phytoplankton cells and its effects on grazers. Freshwater Biology, 38(3), 515-24. https://doi.org/10.1046/j.1365-2427. 1997.00223.x

Hu, Q., Sommerfeld, M., Jarvis, E., Ghirardi, M., Posewitz, M., Seibert, M., \& Darzins, A. (2008). Microalgal triacylglycerols as feedstocks for biofuel production: Perspectives and advances. The Plant Journal, 54(4), 621-639.

Hughes, K. A. (2006). Solar UV-B radiation associated with ozone depletion inhibits the Antarctic terrestrial microalga Stichococcus bacillaris. Polar Biology, 29, 327-336. https://doi.org/10.1007/ s00300-005-0057-6

Khan, M. I., Lee, M. G., Shin, J. H., \& Kim, J. D. (2017). Pretreatment optimization of the biomass of Microcystis aeruginosa for efficient bioethanol production. AMB Express, 7, 19. https://doi.org/10. 1186/s13568-016-0320-y 
Khozin-Goldberg, I., \& Cohen, Z. (2006). The effect of phosphate starvation on the lipid and fatty acid composition of the fresh water eustigmatophyte Monodus subterraneus. Phytochemistry, 67(7), 696-701. https://doi.org/10.1016/j.phytochem.2006.01.010

Li, Y. T., Han, D. X., Hu, G. R., Sommerfeld, M., \& Hu, Q. A. (2010). Inhibition of starch synthesis results in overproduction of lipids in Chlamydomonas reinhardtii. Biotechnology and Bioengineering, 107(2), 258-268. https://doi.org/10.1002/bit.22807

Liang, Y., Sarkany, N., \& Cui, Y. (2009). Biomass and lipid productivities of Chlorella vulgaris under autotrophic, heterotrophic and mixotrophic growth conditions. Biotechnology Letters, 31, 1043-1049. https://doi.org/10.1007/s10529-009-9975-7

Liu, S., Zhao, Y., Liu, L., Ao, X., Ma, L., Wu, M., \& Ma, F. (2015). Improving cell growth and lipid accumulation in green microalgae Chlorella sp. via UV irradiation. Applied Biochemistry and Biotechnology, 175(7), 3507-3518. https://doi.org/10.1007/s12010-015-1521-6

Milano, J., Ong, H., Masjuki, H. H., Chong, W. T., Lam, M., Oh, P., \& Vellayan, V. (2014). Microalgae biofuels as an alternative to fossil fuel for power generation. Renewable Sustainable Energy and Reviews, 58(2016), 180-197.

Muthuraj, M., Selvaraj, B., Palabhanvi, B., Kumar, V., \& Das, D. (2019). Enhanced lipid content in Chlorella sp. FC2 IITG via high energy irradiation mutagenesis. Korean Journal of Chemical Engineering, 36, 63-70.

Naik, S. N., Goud, V. V., Rout, P. K., \& Dalai, A. K. (2010). Production of first and second generation biofuels: A comprehensive review. Renewable and Sustainable Energy and Reviews, 14, 578-597. https:// doi.org/10.1016/j.rser.2009.10.003

Nawrath, M., \& Wu, J. C. (2018). Microbial mutagenesis by atmospheric and room-temperature plasma (ARTP): The latest development. Bioresour. Bioprocess., 5, 1-14.

Ottenheim, C., Nawrath, M., \& Wu, J. C. (2018). Microbial mutagenesis by atmospheric and room-temperature plasma (ARTP): The latest development. Bioresources and Bioprocesses, 5, 1-14.

Parekh, S., Vinci, V. A., \& Strobel, R. J. (2000). Improvement of microbial strains and fermentation processes. Applied Microbiology and Biotechnology, 54(3), 287-301. https://doi.org/10.1007/s002530000 403

Pauline, S., Claire, J.-C., Elie, D., \& Arsène, I. (2006). Commercial applications of microalgae. Journal of Bioscience and Bioengineering, 101(2), 8796.

Qi, F., Wu, D., Ruimin, M., Zhang, S., \& Xu, X. (2018). Characterization of a microalgal UV mutant for $\mathrm{CO} 2$ biofixation and biomass production. Biomed Research International. https://doi.org/10.1155/ 2018/4375170

Qiang, H., Milton, S., Eric, J., Maria, G., Matthew, P., Michael, S., et al. (2008). Microalgal triacylglycerols as feedstocks for biofuel production: Perspectives and advances. Plant Journal, 54, 621-39. https://doi. org/10.1111/j.1365-313X.2008.03492.X

Rahman D. Y., Rachmayati R., Widyangrum D. N., \& Susilanginsih, D. (2020). Enhancement of lipid production of Chlorella sp. 042 by mutagenesis. IOP Conference Series: Earth and Environmental Science. https://doi.org/10.1088/1755-1315/439/1/012021.

Ramaraj, S., Hemaiswarya, S., Raja, R., Ganesan, V., Anbazhagan, C., Carvalho, I. S., \& Juntawong, N. (2014). Microalgae as an attractive source for biofuel production. Environmental Sustainability. https:// doi.org/10.1007/978-81-322-2056-5_8

Rapier, R. (2021). Fuels Still Supply 84 Percent Of World Energy — And Other Eye Openers From BP's Annual Review. Forbes. June 20, 2020. Available online: https://www.forbes.com/sites/rrapier/2020/ 06/20/bp-review-new-highs-in-global-energy-consumption-and-carbon-emissions-in-2019/?sh=18040 50266a1. Accessed on September 1, 2021.

Richmond, A. (2004). Handbook of microalgal culture: Biotechnology and applied phycology. Blackwell Science Ltd.

Rumin, J., Bonnefond, H., Saint-Jean, B., et al. (2015). The use of fluorescent Nile red and BODIPY for lipid measurement in microalgae. Biotechnology for Biofuels, 8, 42. https://doi.org/10.1186/ s13068-015-0220-4

Sarkar, D., \& Shimizu, K. (2015). An overview on biofuel and biochemical production by photosynthetic microorganisms with understanding of the metabolism and by metabolic engineering together with efficient cultivation and downstream processing. Bioresources and Bioprocesses, 2(1), 17.

Saulon, V. (2019). Renewable energy could cut electricity rates by 30\%-report. BusinessWolrd. Available online: https://www.bworldonline.com/renewable-energy-could-cut-electricity-rates-by-30-report/\#: : :text=HEAVY\%20RELIANCE\%20on\%20imported\%20fossil,of\%20a\%20global\%20research\%20ins titute. Accessed on September 1, 2021.

Saxena, S. (2015). Strategies of strain improvement of industrial microbes. In Applied microbiology (pp. 155-171). Springer: New Delhi, India. 
Sharma, K., Li, Y., \& Schenk, P. (2014). UV-C-mediated lipid induction and settling, a step change towards economical microalgal biodiesel production. Green Chem, 16, 3539-3548. https://doi.org/10.1039/ C4GC00552J

Sheehan, J., Dunahay, T., Benemann, J., and Roessler, P. (1978). A look back at the U. S. Department of Energy's aquatic species program-Biodiesel from algae. U. S. Department of Energy's Office of Fuels Development NREL/TP, 580-24190.

Shelly, K., Simon, S., Heraud, P., \& Bardall, J. (2005). Interactions between UVB exposure and phosphorus nutrition I. Effects on growth phosphate uptake and chlorophyll fluorescence. Journal of Phycology, 41, 1204-1211. https://doi.org/10.1111/j.1529-8817.2005.00148.x

Simsek, Y., Lorca, Á., Urmee, T., Bahri, P. A., \& Escobar, R. (2019). Review and assessment of energy policy developments in Chile. Energy Police, 127, 87-101.

Singh, J., \& Cu, S. (2010). Commercialization potential of microalgae for biofuels production. Renewable and Sustainable Energy and Reviews, 14(9), 2596-2610.

Sirikhachornkit, A., Vuttipongchaikij, S., Suttangkakul, A., Yokthongwattana, K., Juntawong, P., Pokethitiyook, P., Kangvansaichol, K., \& Meetam, M. (2016). Increasing the triacylglycerol content in dunaliella tertiolecta through isolation of starch-deficient mutants. Journal of Microbiology and Biotechnology, 26(5), 854-66. https://doi.org/10.4014/jmb.1510.10022 PMID: 26869603.

Srinivas, R., \& Ochs, C. (2012). Effect of UV-A irradiance on lipid accumulation in Nannochloropsis oculata. Photochemistry and Photobiology, 88(3), 684-689. https://doi.org/10.1111/j.1751-1097.2012. 01091.x

Statista. (2021). Oil consumption in the Philippines from 2011 to 2020. Available online: https://www.stati sta.com/statistics/610190/oil-consumption-in-the-philippines/. Accessed on September 1, 2021.

Tayaban, K., Pintor, K., \& Vital, P. (2017). Detection of potential harmful algal bloom-causing microalgae from freshwater prawn farms in Central Luzon, Philippines, for bloom monitoring and prediction. Environment, Development and Sustainability, 20(3), 1311-1328. https://doi.org/10.1007/ s10668-017-9942-8

Tran, Q. G., Cho, K., Park, S. B., et al. (2019). Impairment of starch biosynthesis results in elevated oxidative stress and autophagy activity in Chlamydomonas reinhardtii. Science and Reports, 9, 9856. https:// doi.org/10.1038/s41598-019-46313-6

Van Vandamme, D., Foubert, I., Fraeye, I., Meesschaert, B., \& Muylaert, K. (2012). Flocculation of Chlorella vulgaris induced by high $\mathrm{pH}$ : role of magnesium and calcium and practical implications. Bioresources and Technology, 105, 114-119. https://doi.org/10.1016/j.biortech.2011.11.105

Vaulina, E. N., Anikeeva, I. D., \& Kogan, I. G. (1978). Indut-sirovannyi mutagenez i selektsiya khlorelly (Chlorella Induced Mutagenesis and Breeding). Nauka.

Vigeolas, H., Duby, F., Kaymak, E., Niessen, G., Motte, P., Franck, F., \& Remacle, C. (2012). Isolation and partial characterization of mutants with elevated lipid content in Chlorella sorokiniana and Scenedesmus obliquus. Journal of Biotechnology, 162(1), 3-12. https://doi.org/10.1016/j.jbiotec.2012.03.017

Wang, Z. T., Ullrich, N., Joo, S., Waffenschmidt, S., \& Goodenough, U. (2009). Algal lipid bodies: Stress induction, purification, and biochemical characterization in wild-type and starchless Chlamydomonas reinhardtii. Eukaryotic Cell, 8(12), 1856-1868.

Wong, C. Y., Chu, W. L., Marchant, H., \& Phang, S. M. (2007). Comparing the response of Antarctic tropical and temperate microalgae to ultraviolet radiation (UVR) stress. Journal of Applied Physiology, 19, 689-699. https://doi.org/10.1007/s10811-007-9214-3

Xing, W., Zhang, R., Shao, Q., Meng, C., Wang, X., Wei, Z., Sun, F., Wang, C., Cao, K., Zhu, B., et al. (2021). Effects of laser mutagenesis on microalgae production and lipid accumulation in two economically important fresh Chlorella strains under heterotrophic conditions. Agronomy, 11, 961. https://doi. org/10.3390/agronomy11050961

Yeh, K. L., \& Chang, J. S. (2011). Nitrogen starvation strategies and photobioreactor design for enhancing lipid content and lipid production of a newly isolated microalga Chlorella vulgaris ESP-31: implications for biofuels. Biotechnology Journal, 6(11), 1358-1366.

Yen, H.-W., Hu, I.-C., Chen, C.-Y., Ho, S.-H., Lee, D.-J., \& Chang, J.-S. (2013). Microalgae-based biorefinery-From biofuels to natural products. Bioresource Technology, 135, 166-174.

Zayadan, B. K., Purton, S., Sadvakasova, A. K., Userbaeva, A. A., \& Bolatkhan, K. (2014). Isolation, mutagenesis, and optimization of cultivation conditions of microalgal strains for biodiesel production. Russian Journal of Plant Physiology, 61, 124-130. https://doi.org/10.1134/S102144371401018X

Zaydan, B. K., Sadvakasova, A. K., Saleh, M. M., \& Gaballah, M. M. (2014). Generation and characterization of pigment mutants of Chlamydomonas reinhardtii CC-124. African Journal of Biotechnology, 13(8), 910-915. https://doi.org/10.5897/ajb2013.13002

Zhu, L. D., Li, Z. H., \& Hiltunen, E. (2016). Strategies for lipid production improvement in microalgae as a biodiesel feedstock. BioMed Research International, 2016, 8792548. 
Publisher's Note Springer Nature remains neutral with regard to jurisdictional claims in published maps and institutional affiliations. 